\title{
PSYCHE
}

\begin{tabular}{lll}
\hline Vol. 98 & 1990 & No. 1 \\
\hline
\end{tabular}

\section{COLONY FOUNDATION IN LEAFCUTTING ANTS: THE PERILS OF POLYGYNY IN ATTA LAEVIGATA (HYMENOPTERA:FORMICIDAE) ${ }^{*}$}

\author{
By Alex C. Mintzer
}

5319 85th Ave. \#203, New Carrollton, MD 20784

The huge colonies of Atta leafcutting ants are usually started by independent females under claustral conditions (Huber, 1905; Weber, 1972; Wilson, 1985). Without foraging for supplementary food, the foundress female must rear worker offspring and successfully nurture the fungus culture. Consequently, Atta females are among the largest ants known, with massive thorax and gaster containing fat bodies and flight muscles which are consumed during colony foundation. Only in A. texana (Buckley) does cooperation among females appear to be common during colony foundation. This species has small females relative to other species in the genus, and cooperative pooling of resources may be especially advantageous in this circumstance (Mintzer, 1987). In larger species such as $A$. cephalotes $\mathrm{L}$. and $A$. sexdens L., females usually avoid each other and work independently, even when they land in locally dense aggregations after mating flights (Wilson, 1985; Weber, 1972).

Atta laevigata (F. Smith) is a common leafcutting ant in the savanna and deciduous forest regions of South America and is among the largest species in this genus (Oster and Wilson, 1979; Mariconi, 1970; MacKay, 1986). Herein, I report details of colony foundation in A. laevigata, including the interesting fate of one young colony collected with two dealate females.

\footnotetext{
*Manuscript received by the editor September 15, 1990.
} 


\section{FIELD OBSERVATIONS}

Young colonies of A. laevigata were collected at Simón Bolívar University near Caracas and at Canaima, Estado Bolívar, Venezuela in October 1988. These colonies were initiated by females that flew at the beginning of the rainy season in April or May. Colonies were found in barren soil or lightly vegetated areas away from large shrubs or trees. At Canaima, young colonies of $A$. laevigata were found in savanna and young colonies of $A$. sexdens and $A$. cephalotes at about the same stage of development were found in nearby forest, indicating that these three species probably have their mating flights within a short time period at the start of the rainy season. Young nests of all three species were evidenced by a simple crater $5-8 \mathrm{~cm}$ across. Ten nests of A. laevigata were excavated. A vertical tunnel extended downwards to a single nest chamber at a depth of 20-30 cm. In nine of these nests, the chamber contained a single female and her first brood of workers, which numbered less than 100 ants (minors and medias up to $6 \mathrm{~mm}$ body length), and a roughly spherical fungus garden of $10-50 \mathrm{ml}$ volume with brood. One nest at Canaima had a much larger accumulation of excavated soil on the surface. This crater was connected to a single chamber about $25 \mathrm{~cm}$ deep, which contained a fungus garden of about $100 \mathrm{ml}$ volume. This chamber contained two dealate females and more than 100 workers, with the same size range found in other colonies. This nest was situated within a local cluster of young A. laevigata colonies. The young colonies were retained alive and moved to laboratories in Tucson, Arizona (USA) and Bangor, Wales (UK).

\section{LABORATORY OBSERVATIONS}

The digynous colony and several monogynous colonies adapted to laboratory conditions and began taking food (oatmeal, Nerium oleander and Cynodon dactylon leaves). The fungus gardens remained healthy and were enlarged, and the culture of the digynous colony continued to grow fastest. Brood production and development continued. The two females in the digynous colony could be distinguished on the basis of gaster size (difference about 
$1 \mathrm{~mm}$ ) and thoracic markings, and no aggressive behavior was observed between these two ants. Both females remained on the fungus garden continuously, often standing next to each other for more than an hour at a time. They received similar attention from the workers (riding, grooming, and feeding behavior). In January 1989 , three months after collection, some of the workers suddenly and simultaneously began to attack the legs and antennae of both females. Within $24 \mathrm{~h}$, both ants had lost at least one appendage and were still being attacked. The larger female was removed with some nonaggressive workers when she had lost four legs; at this point, the other female had lost a leg and a complete antenna and was huddled in a small pocket on the fungus garden. Neither ant actively attempted to leave the fungus or the nest, and the workers did not try to remove or evict them from the nest. The females died two and four days after separation; spermathecal examination indicated that both were inseminated. At this point, the digynous colony had over 250 workers and about $200 \mathrm{ml}$ of fungus. Similar aggressive behavior was never observed in monogynous $A$. laevigata colony foundation, nor in concurrent and previous studies of A. texana, cephalotes, mexicana, or sexdens. One surviving colony of A. laevigata had about 31 of fungus culture and produced its first major workers (headwidth $\geq 6 \mathrm{~mm}$ ) in September 1989.

\section{DISCUSSION}

This account of unstable polygyny provides new insight into the evolution of colony foundation strategies in Atta ants, even though it is based on only one nest. First, it demonstrates that one postulated advantage of polygyny (increased productivity of workers and fungus; Mintzer, 1987) applies in field situations. Had the colonies been left in situ, the larger worker force of the digynous colony would have given this colony a considerable advantage in intraspecific interference competition (e.g. brood raiding) within the local cluster of young colonies. However, the two females might not have escaped destruction under any circumstances, given the undiscriminating nature of the worker attack. If digynous colony starts commonly face suicidal ends in A. laevigata and other larger Atta species, cooperative foundation behavior would be discouraged. Worker intolerance of polygyny, coupled with 
indiscriminant execution behavior, might be a more important explanation than female size for the independent colony foundation strategies usually reported in these species. It might also explain why cooperative behavior is rare among the small females of A. mexicana in southern Mexico, where female size is no larger than that found in A. texana (Mintzer et al., in press).

The execution behavior of the A. laevigata workers was very similar to that of $A$. texana workers rejecting a newly introduced queen; however, A. texana worker offspring do not eliminate any females present in the initial colony-founding group. Execution behavior in A. laevigata is very different from that observed in Solenopsis invicta (Buren), where workers selectively target certain supernumerary females and stop before killing the last female (Wilson, 1971). As in S. invicta, high reproductive pheromone levels in small polygynous colonies might trigger execution behavior (Fletcher and Blum, 1983).

\section{SUMMARY}

An incipient colony of the ant Atta laevigata with two foundress females was collected in October 1988. Three months later, the worker offspring attacked and killed both of these foundresses. Similar execution behavior was never observed in A. laevigata colonies founded by single females.

\section{ACKNOWLEDGEMENTS}

I thank the following for assistance in the field: J. Malcolm Cherrett (University College of North Wales), Scott Cameron (Texas Forest Service), and Klaus Jaffe (Simón Bolívar University). Additional help and comments were provided by A. Cedeño, T. Della-Lucia, S. Phillips, and S. B. Vinson. Partial funding for travel to Venezuela was received from the Texas Agricultural Experiment Station at Texas A\&M University.

\section{Literature Cited}

FleTCHER, D. AND M. BLUM

1983. Regulation of queen number by workers in colonies of social insects. Science 219: 312-314. 
HUBER, J.

1905. Über die koloniegrundung bei Atta sexdens. Biol. Centrallblatt 25: 606-635.

MACKAY, W. AND E. MACKAY

1986. Las hormigas de Colombia: Arrieras del género Atta. Rev. Colom. Ent. 12: $23-30$.

MARICONI, F. A. M.

1970. As Sauvas. Editôra Agrinômica, 'Ceres', São Paulo, 167 pp.

MinTZER, A.

1987. Primary polygyny in the ant Atta texana: number and weight of females and colony foundation success in the laboratory. Insectes Soc. 34: 108-117.

Mintzer, A., Deloya, C., Garduño, L. and L. Quiroz

1990. Foundation of colonies of Atta mexicana (Hymenoptera:Formicidae) in the laboratory. Folia Ent. Mexicana (in press).

OSTER, G. AND E. O. WILSON

1978. Caste and Ecology in the Social Insects. Monographs in Population Biology (12). Princeton Univ. Press, 352 pp.

WEBER, N

1972. Gardening Ants, the Attines. Mem. Amer. Philo. Soc. 92: 1-146.

WILSON, E. O.

1971. The Insect Societies. Belknap Press (Harvard) $\mathrm{x}+548 \mathrm{pp}$.

WILSON, E. O.

1985. The sociogenesis of insect colonies. Science 228: 1489. 

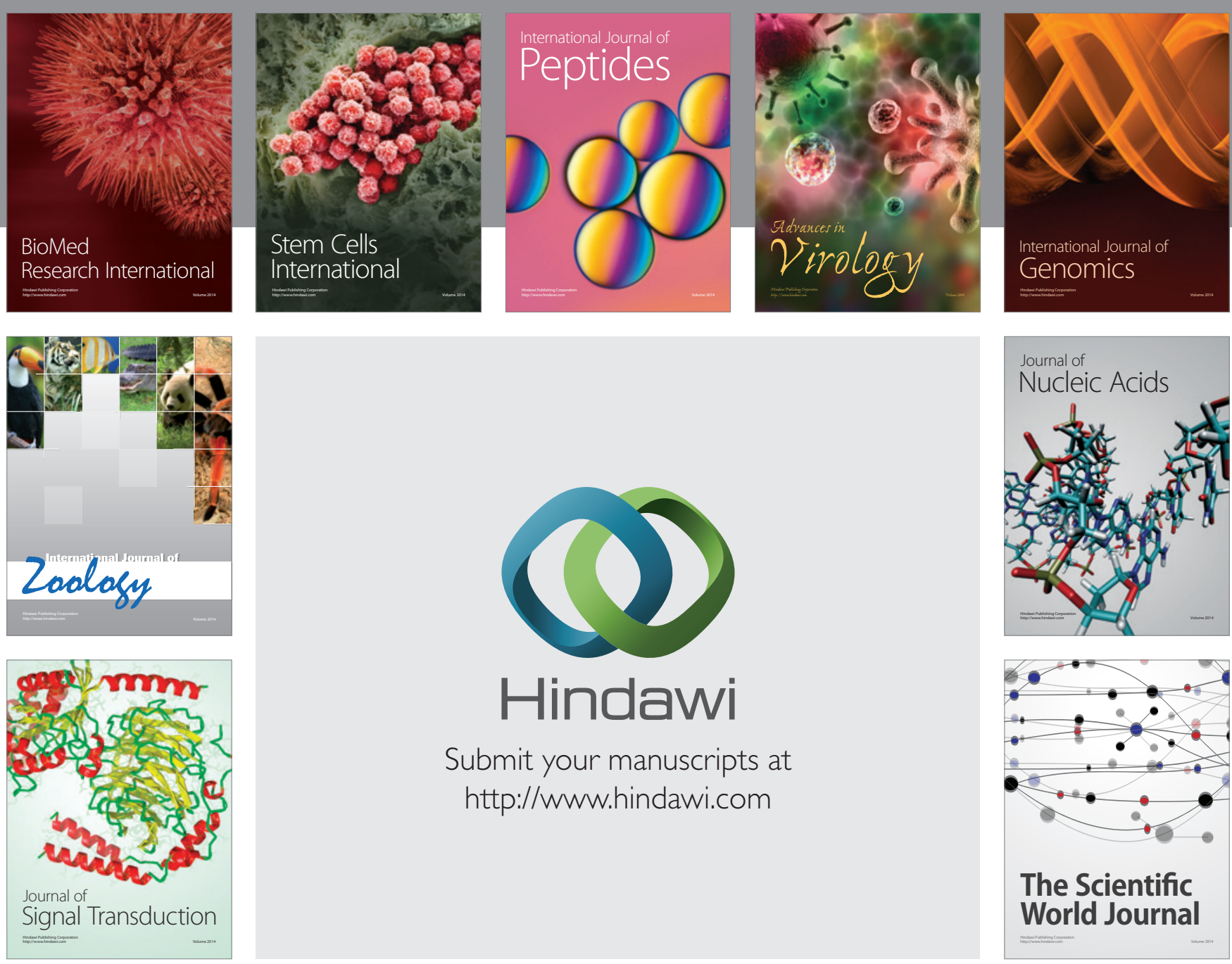

Submit your manuscripts at

http://www.hindawi.com
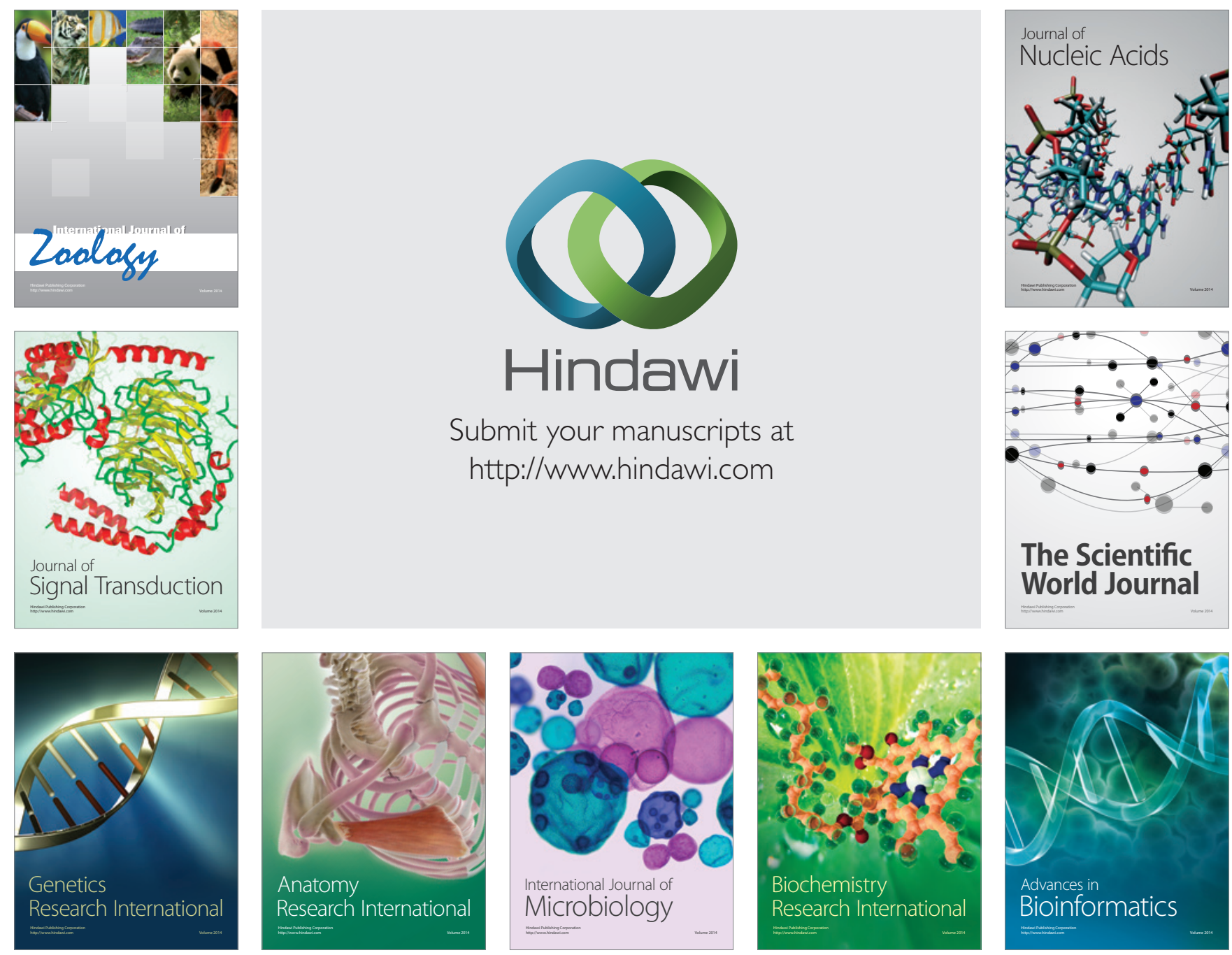

The Scientific World Journal
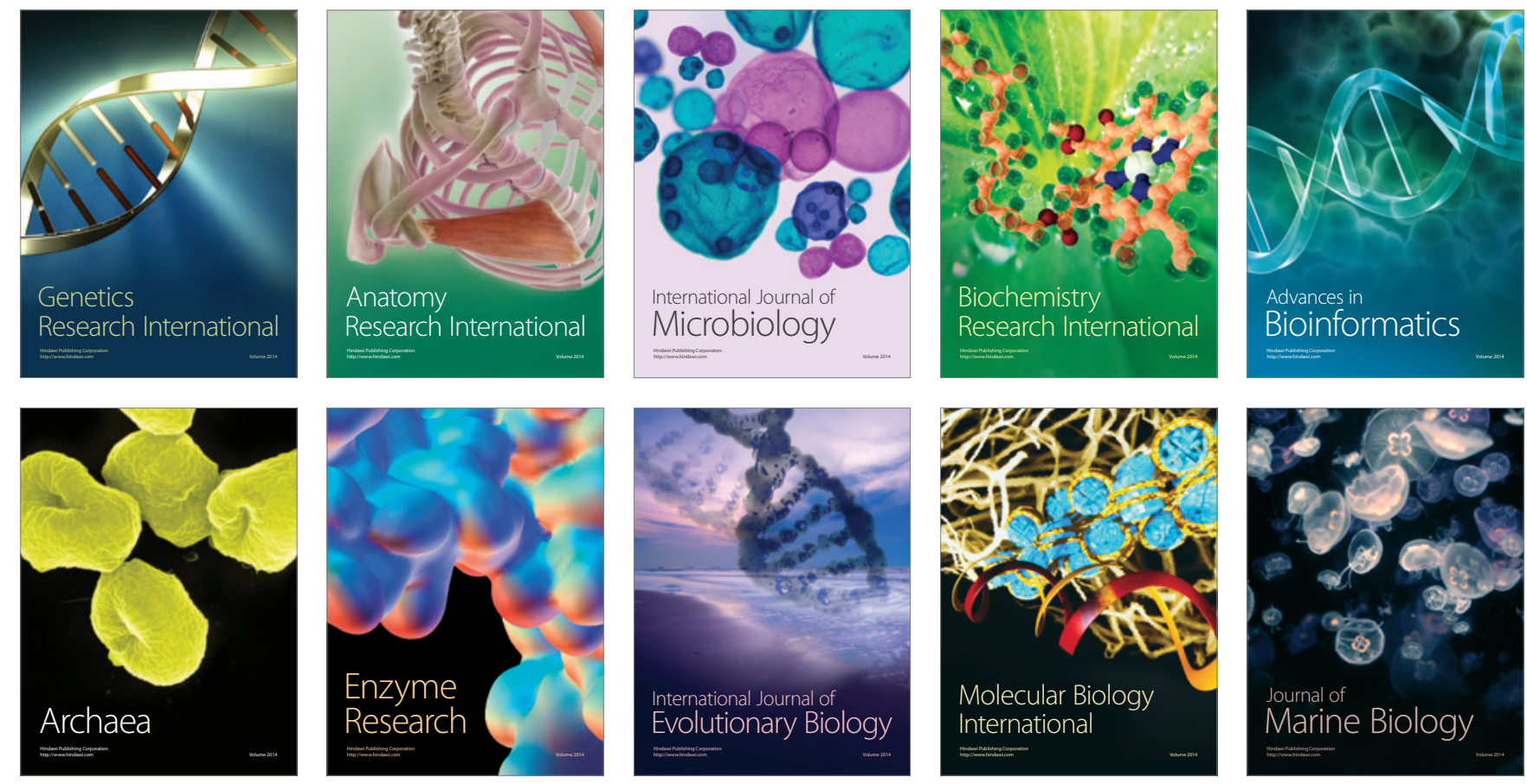